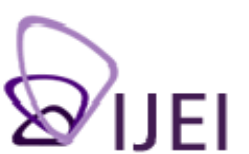

International Journal for Educational Integrity

\title{
Editorial
}

\section{Volume 2, Number 2}

Welcome to the second issue of the International Journal for Educational Integrity for 2006. As we publish this issue, planning is underway for the 3rd Asia-Pacific Conference on Educational Integrity: Creating a culture of integrity, to be held at the University of South Australia, on 6-7 December 2007. Please mark this date in your calendars and consider making a submission for presentation at the conference (the Call for Papers will commence in January 2007). We are very pleased to announce that Professor Cathy Small, from Northern Arizona University, and Associate Professor Brian Martin from the University of Wollongong have both agreed to present keynote addresses to the conference.

Turning to the Journal, the current issue comprises four very different papers. The first, by Sandy Darab at Southern Cross University, is a revised version of a paper presented at the 2nd Asia-Pacific Conference on Educational Integrity. Darab provides an empirical review of an effort to embed a preventative approach to plagiarism in the online assessment of a first year unit. Using action research, and qualitative data that sought to 'capture the lived experience of the students', Darab concludes that incorporating academic skills training within the online environment provides a useful framework for the development of students' understandings of academic integrity.

In the second paper, Julianne East from LaTrobe University offers insight into one of the issues that international students face as they encounter the concept of plagiarism in Australian universities. Using the idea of 'high' and 'low-context' cultures, East proposes that the Australian university is a high-context culture in that understandings of plagiarism and academic conventions are often implicit and taken for granted. Theorising from the perspective of critical pedagogy, East argues further that educators need to uncover and challenge authoritarian practices within the academy which have the potential to marginalise and exclude newcomers.

Neera Handa and Wayne Fallon, both from the University of Western Sydney, provide an expanded and revised version of the paper they presented at the 2nd Asia-Pacific Conference on Educational Integrity. The authors evaluate a development workshop which was designed to orient international students regarding the expectations of their new academic environment. Based on analysis of 39 surveys completed by students at the end of the workshop, and a further 30 follow-up evaluations, the authors recommend repeat workshops as an integral part of the overall program content.

Taking a broader approach to educational integrity, the fourth and final paper by Peter Slade and Chris McConville from the University of the Sunshine Coast, examines the ethical issues of requiring teaching staff to be evaluated by students, using the Student Evaluation of Teaching (SET). They argue that the SET is invalid and ultimately flawed as an evaluation instrument. Slade and McConville conclude that the compulsory administration of the SET is 'a violation of academic freedom and lecturers' rights'.

All four papers make an important contribution to the emerging area of scholarly inquiry known as academic or educational integrity. Both the Darab paper and that of Handa and Fallon have focused on how best to embed academic skills training and development within students' programs of study, while East has theorised the underpinning culture of Australian universities as one which has the potential to exclude outsiders. Slade and McConville take the concept of educational integrity beyond

The International Journal for Educational Integrity is available online at: http://www.ojs.unisa.edu.au/journals/index.php/IJEI/

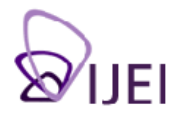


the classroom, by questioning the institutional integrity issues of administering a flawed evaluation instrument.

We thank the authors for their contributions to this issue and look forward to receiving papers for the next issue, due for publication in April 2007.

\section{Editors}

Helen Marsden: helen.marsden@unisa.edu.au

Tracey Bretag: tracey.bretag@unisa.edu.au 